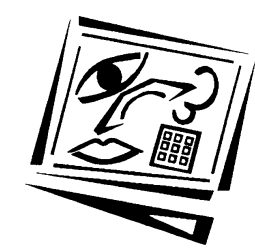

\title{
Can multimedia meet tertiary educational needs better than the conventional lecture? A case study
}

\author{
Geoff Andrewartha and Simon Wilmot \\ Deakin University
}

\begin{abstract}
Educational researchers have long derided the university lecture as an effective mode of delivery of educational materials, but currently there are many reports on the advantages offered by computer. In this study a multimedia solution was sought to replace existing face to face lectures because it appeared to offer a close 'media versus need' match. Consequently, a decision was made to develop a design template for an interactive computer based program that would be suitable for a range of subject content. In order to personalise the instruction, a large video insert was incorporated as the main screen's most prominent design feature. From here the learner could navigate to support material including interactive simulations. The program was piloted with a small group of students and, in particular, the student tracking data that the program automatically generates yield some interesting learning style information.
\end{abstract}

\section{Introduction}

This project's primary aim was to find an effective solution to a teaching and learning problem that was becoming more pronounced each year. Increasingly, the very large cohort of Deakin University first year Media Arts students was presenting with a wider range of experiences and theoretical knowledge of the processes of video editing. Once very expensive and specialised analogue equipment was needed, but the advent of PC-based digital editing systems has resulted in more and more students being exposed to editing principles and operation, both at school and even at home. Coupled with work experience and increased numbers of mature age students returning to study from industry, a 'one size fits all' face to face lecture on the 'theoretical aspects and fundamentals of editing for film and video' was no longer appropriate.

There was a need to cater for the disparate background knowledge of the students, their various learning styles (McLoughlin, 1999), to decrease the 
time spent in class devoted to theoretical issues to allow more time for production, and to meet the university's teaching and learning strategic initiatives, namely to move towards a more flexible delivery of course materials.

A basic instructional design approach of matching need with choice of media was taken. It was also well known that contemporary instructional research is exploring ways to engage learners and limit the extent of the 'sage on the stage' syndrome. Packaging the content into multimedia form would enable more efficient delivery, independent of time and place. However, merely replicating the existing lecture in this mode would not suffice. The educational characteristics of this new medium promised the possibility of value added instruction. It would also enable the learner to tailor the material to their requirements, both in terms of depth and pace. A multimedia program would be able to capitalise on the medium's desirable educational characteristics: learning is individualised, self paced, experiential, and active.

The desire was to produce a more educationally effective outcome. To this end a multimedia program entitled 'The Editing Dimension' was produced using Macromedia Director software and presented on CD-ROM.

A large video insert of the lecturer was to be a key feature of the program's main screen, the objective being not only to personalise the form of communication, but capture some of the inspirational 'feel' of the face to face performance. The hope was that the lecturer's enthusiasm and passion for the subject would also be communicated, even if just simply through the expression on the lecturer's face (Lennon and Maurer, 1994). This was to help break away from the teaching machine idea where the computer is seen as anonymous and unfriendly (Barker and Tucker, 1990). Following from this, critics may ask: 'Why not then just videotape the whole lecture?' Mollison (1997, p.229) offers an answer: "lectures are often too long (and boring) for their full length to be shown on TV or video".

From its inception, this project aimed to address student learning through the incorporation of methods of reinforcement, remediation and enrichment activities. Thus students would be provided with information in a number of forms: mini lecture video clips, written support material with cross referencing, interactive simulations, direction to key references and further reading, and a comprehensive index system acting as an additional access structure to specific content. 


\section{Why choose multimedia?}

There have been several literature reviews concerned with multimedia in the context of interactive instructional technology and its impact on student learning. Overlock (1995), Whitnall et al (1994), and Jones and Smith (1992) summarise the possibilities for enhancement of the quality of the learning experience. "Multimedia... provides educators with the tools to bring learning alive for students" (Lamb, 1992, p. 33).

Lennon and Maurer (1994, p.10) examine the historical development of educational technology and use various criteria to rank effectiveness. They conclude that today's multimedia technology scores exceptionally well on almost all of these criteria. Primarily, multimedia delivery enables students to work actively which represents a "fundamental shift from traditional lecture theatre passivity".

Hypermedia, as Kappe et al (1993) articulate, is the force that puts all previous educational technologies in the shade. Lambert Gardiner (1993, p.68) categorises four generations of media: speech, print, video, and hypermedia. The important point being that "whereas the second generation assists in the creation of a conceptual map of the objective world (verbo-literacy), and the third generation in the creation of a perceptual map (visual literacy), this fourth generation enables us to integrate those maps (verbo-visual literacy)". However, universities have confined themselves largely to the first two generations of media - chalk and talk. The conventional communication settings being the tutorial, the lecture, and the seminar. Lambert Gardiner argues that the hypermedia setting is educationally superior to these because it simulates the real life situation of the student and just as in the real life situation, students are dealing with information from many sources.

Interactive multimedia implies that the shape of the received program is affected by the actions of the user (Tucker, 1990a). Hypertext links would make possible flexibility of use by allowing learners "to explore by self determined linkages" (Barker and Tucker, 1990, p.16). It would be essential that 'The Editing Dimension' design capitalise on this. Students should be able to actively choose program components in whatever desired order, rather than simply work through a pre-determined course of study. Research suggests that a constructivist environment enables learners to gain knowledge more effectively than an instructivist one (Sims, 2000; Pham, 1998; Wilson, 1996). 
The most obvious benefit of interactive multimedia is that "a virtually limitless array of resources can be incorporated into the lesson plan, providing learning experiences that otherwise would be unavailable to students" (Lamb, 1992, p.33). Furthermore, it is a "one box" technology (Ambron, 1990b, p.24) and in addition, multimedia screens can change dynamically. This is a form of delivery going well beyond here are the notes'.

Ambron (1990a, p.17, 18) reminds us that interactive learning is learner centred learning. Citing evidence from cognitive psychologists and educators he concludes that "people find it easier to learn and remember knowledge visually, and that information will stick in a person's memory longer if it is obtained by the learner actively reaching out for and manipulating it rather than being fed passively".

On the other hand, one limitation with developing material for multimedia delivery is the relatively poor resolution of small computer monitor screens. Lennon and Maurer (1994, p.13) suggest that once this is rectified perhaps the "only advantage of going to a lecture in person will be the personal contact with other students and lecturers".

\section{Description of the program}

Upon starting up the computer, students are presented with a logon screen. They enter their name and ID number and are then presented with a 'site' map (a diagram of the program's overall structure and navigation). This takes the learner to the program's main screen. Its key feature is a large video insert of the lecturer that occupies the top right hand quadrant of the screen (see Figure 1). The video is $384 \times 288$ pixels or half PAL size. It is a Quicktime movie compressed with Cinepak at 15fps with a key frame every 15 frames and the data rate limited to a $4 \times \mathrm{CD}-\mathrm{ROM}$.

The clip of the lecturer's introduction immediately starts playing. The video presentation is divided into short discrete sections. These clips are what drive the program and, in addition, aim to preserve one of the more favourable qualities of a lecturer's performance; the ability to enthuse. There are 19 clips which run for a total of 22 minutes, the resultant video file size being $229.5 \mathrm{Mb}$. Clips range from 9 seconds up to 173 seconds in duration with an average length of 69 seconds. Controls underneath the video allow the learner to pause it at any time (perhaps to make notes or think about a point), rewind the video (to review a particular section) or jump forward to 
the next section. Obviously these advantages are not available to the student sitting in a lecture theatre.

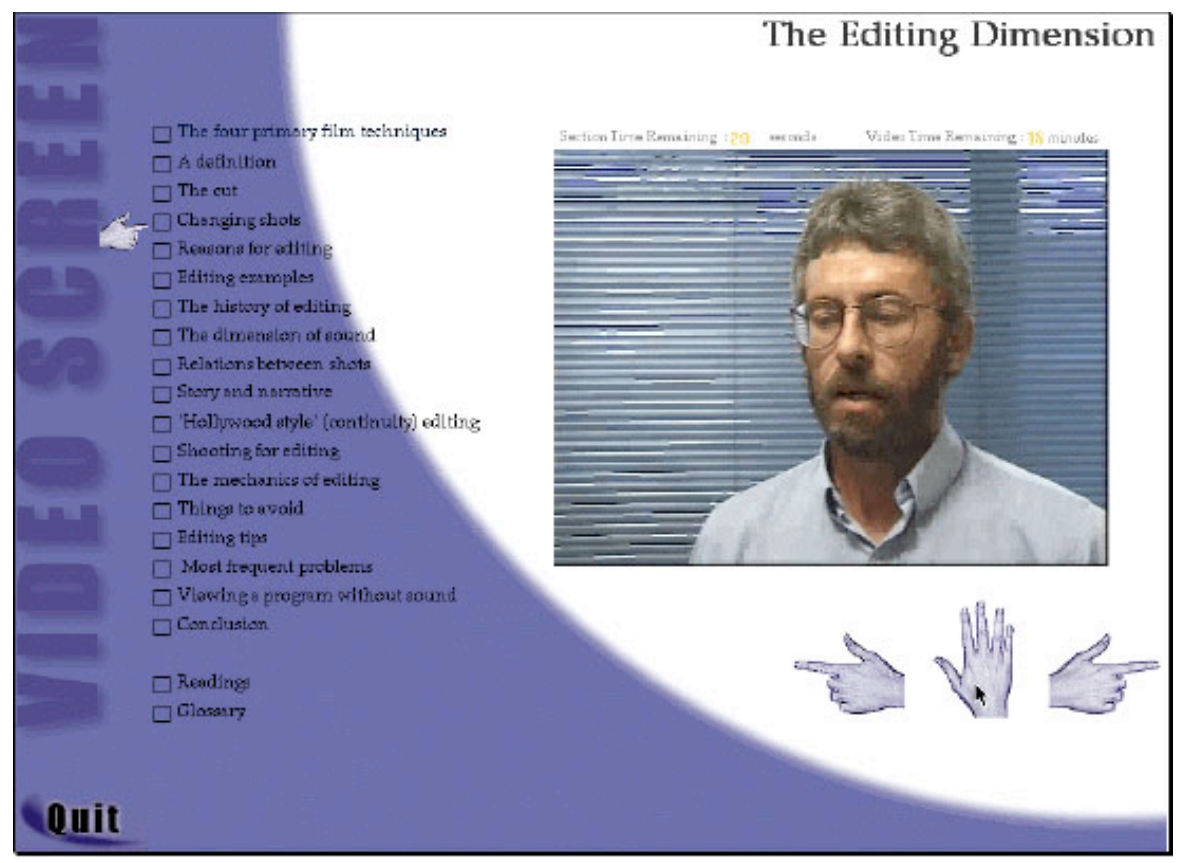

Figure 1: Site map page for The Editing Dimension

Down the left hand side of the screen is a list of the section headings corresponding to each video clip. A pointer moves to its matching section heading as each clip plays. Segments are self contained and do not necessarily need to be viewed in order. At any chosen time, the user can elect to click on a section heading and be taken to the appropriate section screen. Section screens typically consist of a written summary and further information. Some contain interactive simulations which provide experiential learning (perceived as a major strength of the program).

A key design feature is that clicking on the section screen's finish button always delivers users back to the main (video) screen at the exact point where they left. This is made possible by programming that references the Quicktime movie's timecode. Macromedia Director was chosen because of the capacity to directly relate events to Quicktime movie timecode through Lingo, Macromedia Director's scripting language. 
The structure of the program showing the levels of screens is represented schematically in Figure 2.

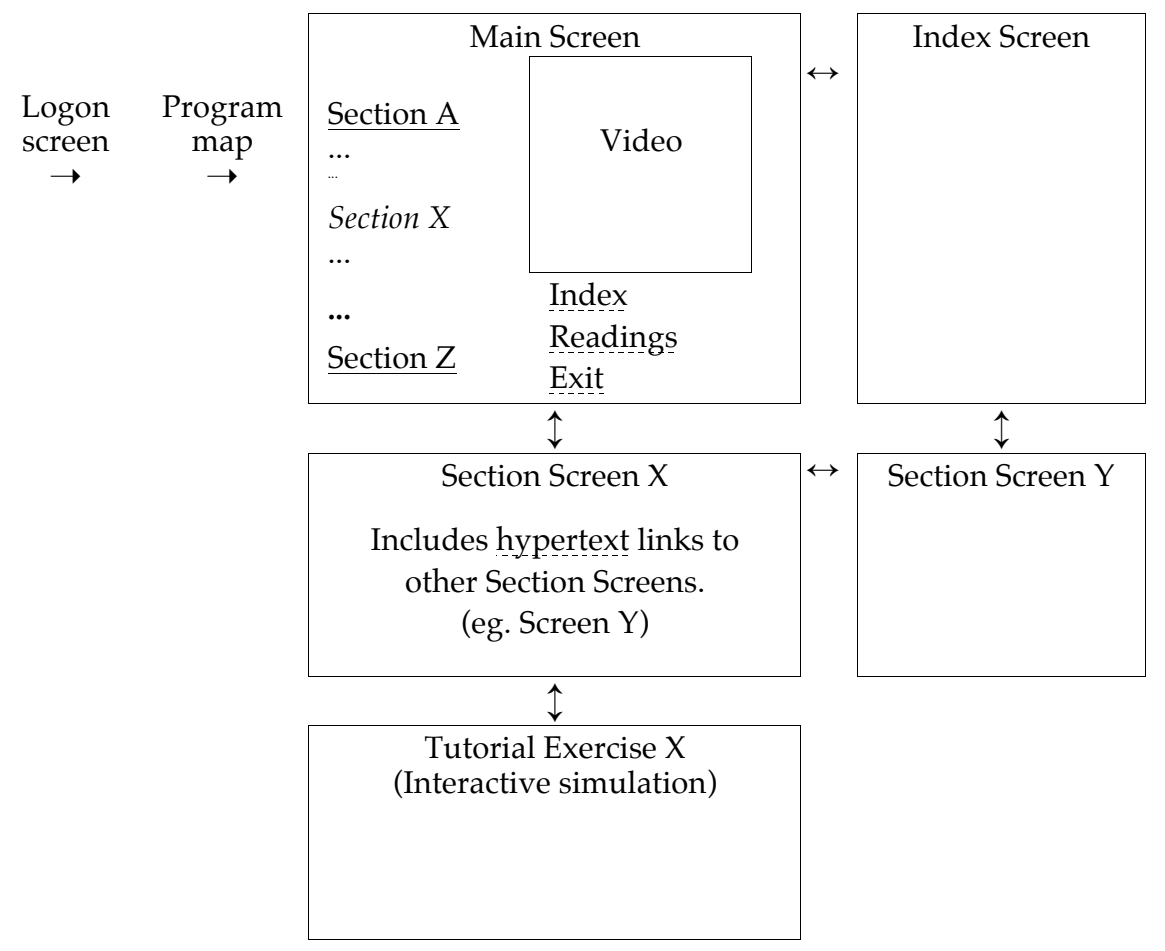

Figure 2: Schematic diagram of the program's navigation

The program automatically places a cross in a check box next to section headings so that learners have a visual record of the sections they have selected.

Throughout the section screen material, keywords have been formatted as hypertext that link to other section screens. These links function as a cross referencing system. Students can follow the chain of links for as many steps as the cross references allow, knowing that the program can step them back to the main video screen. The program also informs explorers how many steps they are away from the originally selected section, via a status line on the section screen. This is another way the program caters for learners who prefer to follow their own path through the content. 
Three tutorial exercises in the form of interactive graphics have also been incorporated into the prototype. Alessi and Trollip (1991) would classify these as "physical simulations". They have been designed to illustrate the editing concepts of 'matching shots', 'crossing the 180 degree line' and 'screen direction'. See Figure 3. Obviously the tutorial exercises do not have to take this form, but the advantages of multimedia include the beneficial learning outcomes that derive from providing learners with simulations and other forms of 'tactile' experiences that generate immediate feedback.

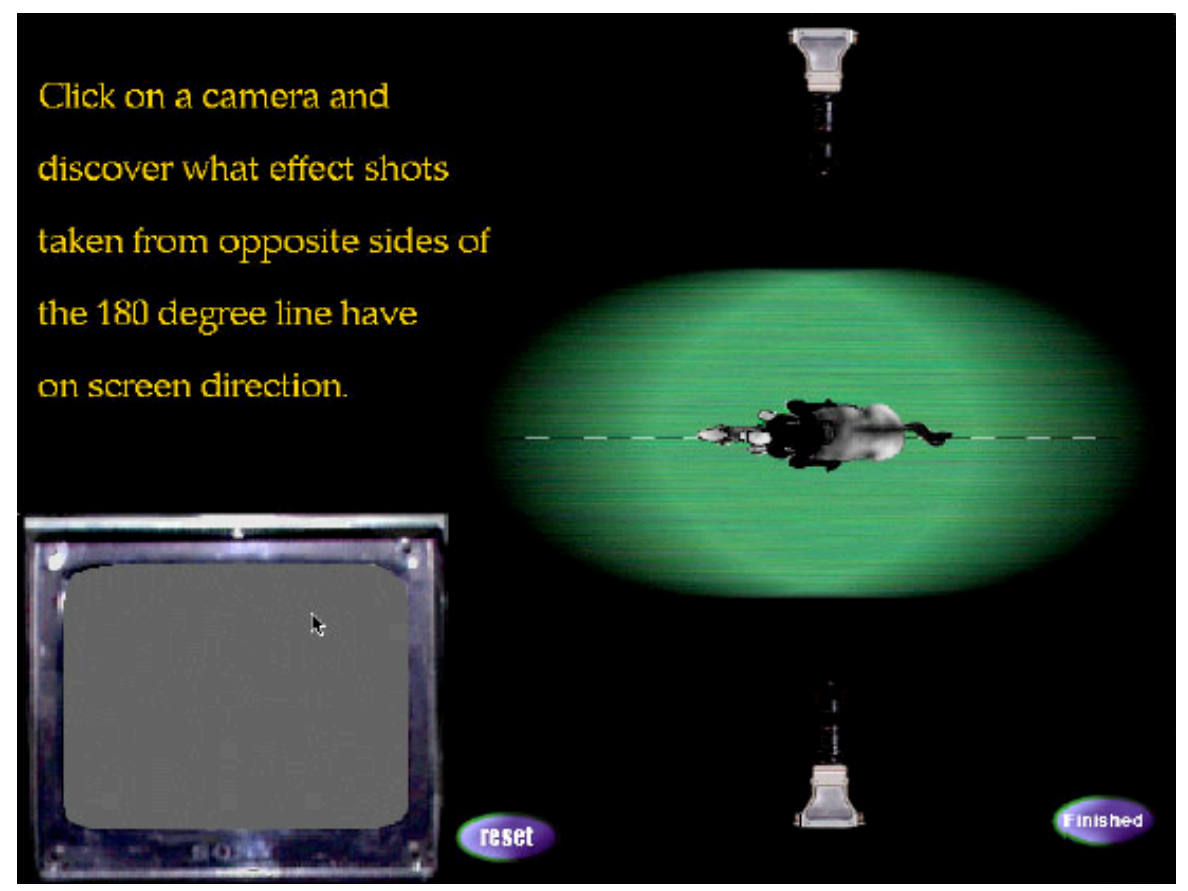

Figure 3: Tutorial exercises in the form of interactive graphics

The index is yet another tool that enables students to access information. This function was not only designed to provide a direct method of access to specific written material, but it was hoped that it might also provide a helpful means of revision.

An important feature of this program for teachers is that it automatically keeps track of the pathway the user has taken through the content. It does 
this by writing to a text file which is linked to the program. Here, all parts of the video watched, all section screens viewed, all hypertext words clicked, all interactives 'played', and all index entries chosen are recorded together with the student's name and ID number that they have entered in the logon screen.

Lingo, Director's computer programming code, records information on the use of the program in Lingo lists and variables. This information is then passed into fields (a Director structure) which is in turn passed on to a generic text file (SimpleText in this case) using Director's PrintOMatic Lite extra. This text file resides on the host computer's hard drive. If the file exists, then data are appended to the end of the file, including the student's name and ID, which then differentiates data on different students. If the file does not exist, the PrintOMatic extra creates it. This file can then be assessed and removed whenever the instructor chooses. In its existing form, the file is not secure, but in tests the host machines were under supervision, therefore negating the need for security. Clearly this is an issue for further development.

Development and testing took place with Macintosh PowerPC 7200/120s, which had $32 \mathrm{Mb}$ of RAM, $4 \times$ CD-ROM drives, headphones, and 17 inch monitors running a screen resolution of $600 \times 800$. A specification for a minimum system requirement was not determined.

\section{Design considerations and lessons learnt from the production process}

Development began with discussion that concentrated on the various essential components of the face to face lecture. This included identifying key facts to be presented, the order of development of concepts, and so on. The content was then 'chunked' into discrete sections. It was also known that images and graphics are better suited to display on a video monitor than is text, so there was a desire to decrease the textual components as much as possible.

Thorough planning on paper was found to be absolutely necessary and a schematic diagram, which incorporated elements of a storyboard and a flow chart, began to emerge. The design and development of multimedia courseware can be a very complex task (Nicholson and Ngai, 1996). It cannot be overstated that it is much easier to revise content at this stage than when in the multimedia authoring stage. 
It then became of paramount importance to establish the number of levels of screens that would be needed. The video component was to be an integral element and so every endeavour was made to link items to the main screen. The guiding philosophy was that the further away students are taken from the main screen, the more lost and disoriented they would be likely to feel. Consequently, the aim was to keep the number of levels of screens to a minimum. Research suggests that if too many levels are offered, the user is likely to quit, suffering 'choice fatigue' (Ingram, 1995). Hence, a key design step in this production was to decide on using a main screen and only two levels of support screens.

Consideration was given to how students might interact with the program. The learning material is actually shaped by the process of 'reading' it. Borrowing Kemp's (1993, p.161-163) terminology from his research into the study strategies of distance education students who were using print based study guides, users might be either "serialists" (students who employed a largely linear approach and relied more heavily on the text's structure to direct their learning) or "selective samplers" (students who employed a non-sequential study route). The research literature in multimedia reports that the same phenomenon is observed with electronically presented material (Lamb, 1992).

If users have only one path to follow they can adopt a passive attitude (Bartolome, 1993, p.55). On the other hand, Bartolome found, when researching interactivity levels and learning styles, that giving learners too much freedom to select their path can "generate insecurity" even in adult learners. Consequently, the design principle adopted was that students would be 'guided' in their learning by the program, but have a certain amount of freedom to make conceptual connections between component parts of the content. This feature is in line with Bennett and Brennan's (1996) thinking. Their interactive program also featured a navigational structure that was largely linear with diversion branches.

The initial trials at videotaping the mini presentations yielded useful information that would ensure that future presentations to camera were done more efficiently and result in improved technical quality. Of particular interest was that the lecturer reported being quite apprehensive at the thought of being videotaped. The medium was perceived to be more threatening than facing a whole lecture theatre of students. Ad libbing was found to be too difficult due to the constraint of time; the delivery of information had to be very efficient with no padding. In the end the presentation was scripted verbatim. The lecturer then had to be instructed 
to compensate for this lack of spontaneity otherwise a flat performance resulted.

It was recognised too that there were differences in the types of delivery techniques that would work effectively in the face to face setting compared with how they would function on video. For example, an attempt to retain some of the jokes and humour present in the original lecture was tried, but soon abandoned. Bennett and Brennan (1996) came to a similar conclusion.

It was imperative that the program function in a logical way even if the student had jumped around erratically in the content. The program had to be smart enough to keep track of such wild excursions from the main path and make certain that the users would never feel like they were lost in a maize. Hence, the program would be required to keep a record of each part of the presentation that was visited and allow them to quickly and exactly retrace their steps. Some sophisticated programming was needed to accomplish this because the finish button needed to function appropriately in accordance with the student's previous move. Because of this it was a relatively easy programming task to have these actions recorded in an externally linked text file. In this way the 'user tracking' records students' study paths.

The advantages of this added functionality are many fold. Printouts of the 'user tracking' can be used to identify areas of the content covered and areas not looked at by individual students, identify sections of content that were perhaps difficult for students to grasp because they were accessed more than once, establish group trends in program interaction by pooling many individual records, point to possible areas of weakness in the conceptional content of the material itself, identify the learning style of individual students, determine how engaging the program really is, provide information for further revision of the content, and so on.

Navigation is "the art of knowing where you are" (Tucker, 1990b, p.134). To aid in this an explanatory screen was added to provide students with a clear idea of how the program is physically constructed to decrease the disorientation that is often reported as accompanying the use of hypertext systems. The navigation problems that users can experience include "experiencing difficulty in gaining an overview; being unable to find information that is known to exist; and having difficulty in determining how much information on a given topic exists, how much of it has been seen, and how much is left" (Kappe et al, 1993, p.53). 
Because the program's template and layout design was to be re-useable for other content, standardised backgrounds for all screens were prepared. There was no doubt that 'The Editing Dimension' would be judged on how it looked on screen. The interface needed to be aesthetically pleasing with elegant typeface, design and layout. The learners too would make value judgements, especially computer game players and Internet users. Their expectations would be high. An integral part of learner engagement includes design elements like colour (and colour changes), background textures, style and the readability of on screen text, using animation on interface controls, and the like.

Attention was also paid to the readability of text on screen. Much has been written in the literature on the 'ergonomics of use' of text electronically displayed on a computer screen (Andresen, 1991; Goodall and Smith Reilly, 1988; Hartley, 1987; Jonassen, 1985; Lancaster and Warner, 1985). Because the aspect ratio of a computer screen is not the same as a printed page, careful consideration was given to the numerous design concerns of displaying text electronically. It needed to be clearly layed out and 'comfortable' to read on screen for extended periods. The text screens were made deliberately simple with large amounts of white space to make the text easier to read. This was in line with research recommendations (Bennett and Brennan, 1996, p.11; Pellone, 1995, p.76-78).

The traditional face to face lecture included a number of diagrams on overhead transparencies that needed quite a bit of explanation by the lecturer. These two dimensional line drawings were limiting because they were representing three dimensional objects in the real world that actually moved and changed. For example, in one case, students needed to imagine different camera views of a subject when camera positions were changed. Of course these diagrams could have been scanned into a section screen and accompanied with a written explanation, but this would have been even less effective at communicating these concepts than the lecturer in the lecture theatre discussing whilst pointing to parts of the diagram, scribbling on it and so on.

This type of content virtually identified itself as being eminently suitable for packaging as interactive tutorial exercises, going beyond static representations to user controlled dynamic simulation (Whitnall et al, 1994, p.721). The computer can mediate between the perceptual and conceptual world in our heads and complex objective real world situations, making the latter more easily understood (Lambert Gardiner, 1993). If students 
could interact with the graphic, move things around, and change settings, they could observe first hand the outcome of their actions and this potentially would make for even better learning outcomes than the lecturer's original exposition (Pellone, 1995).

The production team saw these 'interactives' as potentially being the program's most powerful instructional elements, but a number of criteria needed to be taken into consideration in their planning. Where practicable, these simulations should:

- have intuitive controls

- encourage with feedback. For example, reward the student for correct responses, perhaps through sound - as used with the three simulations 'built' for this program. Feedback from the computer "makes their eyes light up" (Mohl, 1990, p.131).

- provide remediation (for example, by way of a written description) should students need it

- allow students a 'tactile' experience by manipulating on screen elements

- let students discover outcomes rather than being too didactic

- create situations that require problem solving

- take the form of a simulation of the real world event.

The key to good interface design is to ensure that the things the users want to do are obvious. In theory, concrete manipulation can lead to a shift in the learner's level of cognitive thinking, permitting abstract construction. Of course to some learners, interaction with the medium itself brings its own rewards and intrinsic motivations: the pleasure of playing, engagement with the program, the challenge to their skills, and the fun of engaging with the hardware (Greenfield et al, 1994).

A useful feature of the program is its extensibility. With the basic structure constructed, additional functionality could always be added later as desired. For example: self test items, whole reference articles, sample video clips, remediation screens, a search engine, and a glossary could easily be set up.

\section{Advantages of the asynchronous delivery mode}

The advantages of time delayed delivery are obvious: the lecture can be delivered on demand, delivery is not restricted to any particular time or space, it can be paused and replayed, text can be studied carefully and in 
depth, feverish and inaccurate note taking is abolished, learning is self paced and active, it is cost effective for large enrolments, and so on. Yet, the face to face mode allows for changes to be made on the fly, is quicker to prepare and easier to revise, humour and entertainment elements can be incorporated, and it is a social and communal gathering (Cockburn and Ross, 1976a, 1976b; Costin, 1972).

\section{Evaluation of the multimedia program}

Initial feedback was received by showing the program to colleagues. Several asked 'what is the video doing, why not just have a few still pictures?' This prompted further reflection on the way the video component functions and the conclusion that the computer demands this sort of visual element. Users expect a visually appealing display; students generally regard text only pages as boring.

The program was piloted with representative students. Two groups of volunteers were sought from the first year Media Arts unit, Moving Images. One volunteer group (12 students) interacted with the 'The Editing Dimension' multimedia CD-ROM program (they also later attended the face to face lecture and so did not suffer any educational disadvantage) whilst the other group (20 students) was drawn from those students who would only attend the conventional one hour face to face lecture as normal. The trial with the CD-ROM group and associated assessment was completed before the timetabled lecture took place. In forming these groups, it must be acknowledged that no attempt was made to obtain a statistically random sample. Further, the multimedia program effectively covered the same content contained in the face to face lecture on which it was based.

To ascertain entry level knowledge, a test was administered to both groups in the week prior to being exposed to any instruction. The same test was again given to both the CD-ROM program group and the face to face lecture group, immediately after their respective modes of instruction. Selection of evaluation methods was influenced by the work of Bennett and Brennan (1996), Nicholson and Ngai (1996), and Rees (1995).

A short questionnaire was also distributed to the CD-ROM group in order to supplement data received from the pre- and post-test regimen. The questionnaire was designed to elicit attitudes and opinions and was based on the methodology outlined by Oppenheim (1996) and Bell (1987). Previous researchers have also used this approach, see for example, 
Whitnall et al (1994, p.724-725). User tracking data for each participating student was printed out and descriptive statistical analysis was performed on the questionnaire and test data.

The goal was not only to establish how easy the program was to use, but also how effective it was as a teaching tool, however, the use of comparative approaches between media has been strongly contested in instructional research for almost two decades now, so direct comparison of the pre-test and post-test data obtained from students attending the face to face lecture with data obtained from students using the CD-ROM itself, must be treated cautiously. This is because fundamentally different things are happening in a face to face lecture compared with what an individual student experiences using a computer based product. Nevertheless, the team was anxious to gain at least a crude global impression as to the educational effectiveness of the new form of delivery.

Some observations were also made whilst the students were interacting with the multimedia program, but for the most part they were left alone and could choose to leave at any time they wished. A booking of two hours was made for each participant with students being given only a general indication that it might take between one and two hours of their time for the task. Some informal discussion also took place with the multimedia participants.

The CD-ROM and lecture cover theoretical aspects of editing. Of course, one would expect application of these principles in students' practical production projects, but measurement of this is highly problematic.

\section{Analysis of the test data and questionnaire}

The average multimedia program group pre-test mark was $25 \%$ and posttest mark was $62 \%$. Whereas the average face to face group pre-test mark was $24 \%$ and post-test mark was $38 \%$ ( and somewhat disappointing). Hence, it appears that the multimedia group improved their mark by a greater margin than the face to face group.

Of course it could also be assumed that the multimedia students were the more conscientious students because they willingly volunteered for this study, in addition to their normal workload. For this reason care should be taken when interpreting the magnitude of these changes. However, it can 
safely be concluded that the multimedia program has communicated new knowledge at least as well as the face to face lecture and probably better.

Questionnaire responses shed further light. Students generally rated the experience of using the program as enjoyable and their level of engagement with it quite high. They were happy with the clarity of the instructional content presented and most said they preferred the experience of working with the program over that of attending a face to face lecture. Interestingly, most also said that they made more notes than they would have normally done in a conventional lecture.

Very few respondents gave negative responses when asked to entertain the suggestion that the multimedia program replace the traditional face to face lecture. All respondents reported that the multimedia program had improved their understanding of the subject matter. Nine out of twelve respondents rated the program as positively supporting their individual learning style.

The features that most students liked about the program included the ability to pause and rewind the video, the 'participative' nature of the program, and the comprehensive support notes (although students preferred the section material that was written out in full prose rather than presented as a dot point summary).

\section{Analysis of the user tracking data}

The average time spent with the program for the twelve students was one hour and twenty five minutes. Whilst two students spent only a little over half an hour, most spent an hour or more with the program. Two students managed over two hours. This was very encouraging because the students were not supervised and were free to leave at any time. At least the experience appeared to be engaging.

A graphical trace for each student was produced from the tracking data that was automatically recorded in the text file that was linked to the main teaching program. Each element 'visited' was manually plotted on a grid using an identifiable symbol and then joined by a line to produce the graph. These graphical traces show at a glance the path taken through the content by each student. A variety of study paths is discernible, ranging from methodical to a more exploratory approach. Trends are also observable with the number of hypertext links, simulations and index links accessed. 
Two main trends in student approaches stand out. One group seemed to place most importance on the video component. Eight of the twelve students effectively began by watching all the video clips through in their entirety and in the order presented. One student in this group viewed all twice through in order before exploring other parts of the program. Three students did quite a bit of re-playing of parts of clips, presumably ensuring that they did not miss any points, but still viewed them through in order. This group then set about, by and large systematically, to look at the section screens.

The other group (four out of twelve students) still placed importance on the video clips, but essentially chose to view a clip and then look at its corresponding support screen. Again, as with the previous group, all students ended up viewing all clips.

The average number of section screens viewed by students was twelve out of the seventeen. Four students visited them all. Disappointingly, only five out of twelve accessed the simulations. Responses from those who did, said that they really enjoyed these 'interactives' and rated their teaching effectiveness highly. Such a low 'hit rate' for these was blamed on their poor signposting. Many students reported that they simply did not know of their existence. The addition of hot links directly off the main video screen is an obvious solution. Probably for similar reasons, only five out of twelve students made use of the hypertext index facility.

Unexpectedly, no student followed a path that could be described as 'erratic', 'jumping' or even 'non-conventional'. Even for the students who really explored the hypertext links between section screens, their overall coverage of the material was both thorough and reasonably sequential due to the way they progressed through the video component. There were no wild excursions taken.

It is not possible to determine from the linked user tracking file how long students are spending looking at section screens. In the next version of the program, getting the time from the computer's internal clock stamped to the user log file after every action the student makes would yield even more valuable data on student patterns of use.

\section{Conclusion}

The goal of the study was to determine whether the multimedia program would provide an educationally better solution than the face to face lecture. 
As reported, asynchronous delivery does provide decided advantages for both students and faculty. Importantly, the multimedia program was found to better cater for an increasingly less homogeneous student cohort. Students also enjoyed the experience and test data indicate learning outcomes at least as favourable as those from the lecture.

\section{Future directions}

The design of a front end program to automate the process of incorporating the content into the template would be beneficial. Designing an 'automatic builder' would mean that the lecturer would simply pour content into the relevant proforma box and then allow the utility program to build the sections. Much less knowledge of Macromedia Director software would then be necessary.

Further investigations are needed. How easy is it to revise and update the content of the prototype? Is the template adaptable and flexible enough to allow for a wide variety of subject matter? Can the program be successfully delivered online (via broadband, intranet, or Internet)? If the program is embedded in an Internet browser, how can the problems of streaming video whilst preserving real time interactive functionality be overcome?

Online delivery is required. Economics is likely to favour telecommunication based education over traditional lectures because telecommunication costs are falling as costs of staffing, educational real estate, public funding, and transport are rising. Further, changing student expectations, global competition, and the need for continuous life long learning all contribute to the push towards the utilisation of online multimedia technology.

\section{Acknowledgment}

Funding for this research was provided by eMERGE, the Victorian Government's multimedia cooperative.

\section{References}

Alessi, S. M. \& Trollip, S. R. (1991). Computer-based instruction: Methods and development (2nd ed). Engelwood Cliffs, New Jersey: Prentice-Hall.

Ambron, S. (1990a). A short history of hypermedia. In J. Barker \& R. N. Tucker (Eds), The interactive learning revolution: Multimedia in education and training. New York: Nichols. 
Ambron, S. (1990b). On multimedia in education. In J. Barker \& R. N. Tucker (Eds), The interactive learning revolution: Multimedia in education and training. New York: Nichols.

Andresen, L. W. (1991). Issues in text design and layout for computer based communications. Distance Education, 12(2), 252-256.

Barker, J. \& Tucker, R. N. (Eds) (1990). The interactive learning revolution: Multimedia in education and training. New York: Nichols.

Bartolome, A. R. (1993). Learning styles: Interactivity and path control. In H. Maurer (Ed), Proceedings of ED-MEDIA 93, 52-59.

Bell, J. (1987). Doing your research project: A guide for first-time researchers in education and social science. England: Milton Keynes, Open University Press.

Bennett, S. J. \& Brennan, M. J. (1996). Interactive multimedia learning in physics. Australian Journal of Educational Technology, 12(1), 8-17. http: / / cleo.murdoch.edu.au/gen/aset/ajet/ajet12/ wi96p8.html

Bligh, D. A. (1972). What's the use of lectures? Harmondsworth: Penguin.

Cockburn, B. \& Ross, A. (1976a). Teaching in higher education Series (1) Lecturecraft. England: University of Lancaster.

Cockburn, B. \& Ross, A. (1976b). Teaching in higher education Series (2) Why Lecture? England: University of Lancaster.

Costin, F. (1972). Lecturing versus other methods of teaching: A review of research. British Journal of Educational Technology, 1(3), 4-31.

Goodall, H. \& Smith Reilly, S. (1988). Writing for the computer screen. New York: Greenwood Press.

Greenfield, P. M., Camaioni, L., Ercolani, P., Weiss, L., Lauber, B. A. \& Perucchini, P. (1994). Cognitive socialization by computer games in two cultures: Inductive discovery or mastery of an iconic code? Journal of Applied Developmental Psychology, 15, 59-85.

Hartley, J. (1987). Designing electronic text: The role of print-based research. Educational Technology and Communication Journal, 35, 3-17.

Ingram, F. (1995). Eloquent interfaces. Metro Magazine, 103, 88.

Jonassen, D. H. (1985). Electronic display of text. In D. H. Jonassen (Ed), The technology of text Vol. 2. (pp. 287-291). Englewood Cliffs, NJ: Educational Technology Publications.

Jones, L. J. \& Smith, S. G. (1992). Can multimedia instruction meet our expectations? EDUCOM Review, Jan-Feb, pp. 39-43. 
Kappe, F., Maurer, H. \& Sherbakov, N. (1993). Hyper-G: A universal hypermedia system. Journal of Educational Multimedia and Hypermedia, 2(1), 36-66.

Kemp, N. (1993). Typographical features within instructional texts and their influence on the study techniques adopted by distance education students, Master of Science Thesis, Western Australia: Curtain University of Technology.

Lamb, A. C. (1992). Multimedia and the teaching-learning process in higher education. In Teaching in the information age: The role of educational technology. New Directions for Teaching and Learning Number 51. The Jossey-Bass Higher and Adult Education Series. San Francisco: Jossey-Bass Publishers.

Lambert Gardiner, W. (1993). Using hypermedia to turn university teaching inside out. In N. Metallinos (Ed), Verbo-visual literacy: Understanding and applying new educational communication media technologies. Selected Readings from a Symposium of the International Visual Literacy Association, June 25-29, pp. 6572, Delphi, Greece.

Lancaster, F. W. \& Warner, A. (1985). Electronic publication and its impact on the presentation of information. In Jonassen, D. H. (Ed), The technology of text Vol. 2, pp. 292-309, Englewood Cliffs, NJ: Educational Technology Publications.

Lennon, J. \& Maurer, H. (1994). Lecturing technology: A future with hypermedia. Educational Technology, April, 5-14.

McLoughlin, C. (1999). The implications of the research literature on learning styles for the design of instructional material. Australian Journal of Educational Technology, 15(3), 222-241.

http: / / cleo.murdoch.edu.au / ajet/ajet15/mcloughlin.html

Mohl, B. (1990). Thoughts on multimedia authoring. In J. Baker \& R. N. Tucker (Eds.) The interactive learning revolution: Multimedia in education and training, New York: Nichols.

Mollison, M. (1997). Producing videos: A complete guide, Sydney, Australia: Allen and Unwin, AFTRS.

Nicholson, A. Y. W. \& Ngai, J. Y. K. (1996). Managing the development and production of interactive courseware in education. Australian Journal of Educational Technology, 12(1), 35-45. http: / / cleo.murdoch.edu.au/gen/ aset/ajet/ ajet12/ wi96p35.html

Oppenheim, A. N. (1966). Questionnaire design and attitudinal measurement. London: Heinemann.

Overlock, T. H. Sr. (1995). Development of a multi-year plan for the integration of multimedia technology at Northern Maine Technical College. Ed.D. Dissertation. pp. 55-73, US, Maine: Nova Southeastern University. 
Pellone, G. (1995). Educational software design: A literature review. Australian Journal of Educational Technology, 11(1), 68-84.

http:/ / cleo.murdoch.edu.au/gen/aset/ajet/ajet11/ wi95p68.html

Pham, B. (1998). Quality evaluation of educational multimedia systems. Australian Journal of Educational Technology, 14(2), 107-121. http:/ / cleo.murdoch.edu.au/ajet/ajet14/pham.html

Rees, K. (1995). Design issues in computer based education. Australian Journal of Educational Technology, 11(1), 28-35.

http: / / cleo.murdoch.edu.au/gen/ aset/ajet/ ajet11/wi95p28.html

Sims, R. (2000). An interactive conundrum: Constructs of interactivity and learning theory. Australian Journal of Educational Technology, 16(1), 45-57. http:/ / cleo.murdoch.edu.au/ajet/ajet16/sims.html

Tucker, R. N. (1990a). On interactivity and open learning. In J. Barker \& R. N. Tucker (Eds), The interactive learning revolution: Multimedia in education and training. New York: Nichols.

Tucker, R. N. (1990b). Navigation. In J. Barker \& R. N. Tucker (Eds), The interactive learning revolution: Multimedia in education and training. New York: Nichols.

Wilson, B. G. (Ed) (1996). Constructivist learning environments: Case studies in instructional design. Englewood Cliffs, NJ: Educational Technology Publications.

Witnall, R., Fernandes, E., Almassizadeh, F., Love, J., Dugan, B., Sawrey, B. \& Wilson, K. (1994). Multimedia chemistry lectures. Journal of Chemical Education, 71(9), 721-725.

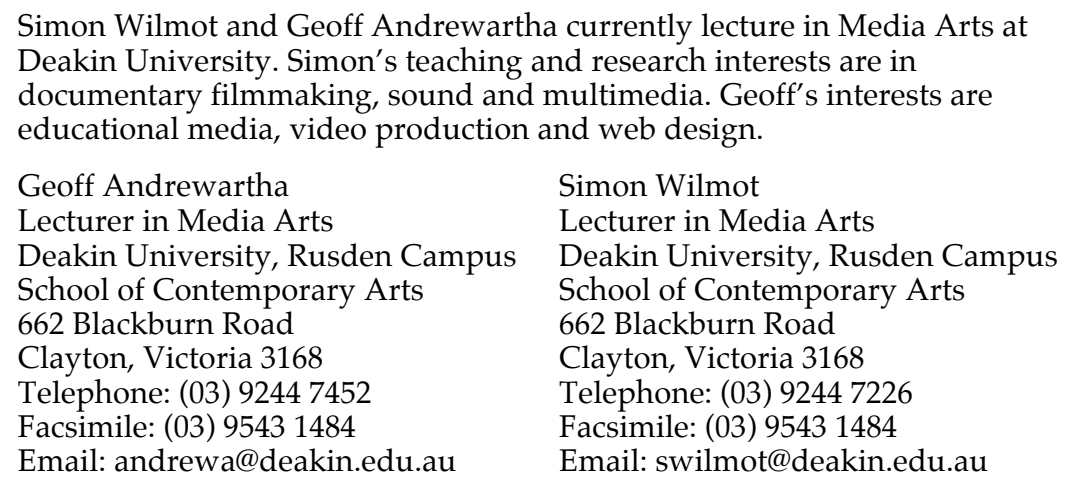

